\title{
Effect of scaling on the invasion of oral microorganisms into dentinal tubules including the response of pulpal cells_an in vitro study
}

\author{
Alexandra Stähli ${ }^{1}$ (D) - Alex S. J. Schatt ${ }^{1} \cdot$ Miro Stoffel $^{1} \cdot$ Sandor Nietzsche $^{2} \cdot$ Anton Sculean $^{1} \cdot$ Reinhard Gruber $^{1,3}$. \\ Barbara Cvikl $^{4} \cdot$ Sigrun Eick ${ }^{1}$
}

Received: 1 August 2020 / Accepted: 24 November 2020 / Published online: 4 December 2020

(C) The Author(s) 2020

\begin{abstract}
Objectives To investigate how scaling affects the penetration of microorganisms into dentinal tubules, how pulpal cells seeded into the pulp cavity respond to bacterial challenge, and how penetration and inflammatory response may depend on the bacterial composition.

Materials and methods Root canals of 102 extracted human teeth underwent shaping and cleaning. Half of the teeth were subjected to scaling and root planing, the other half remained untreated. Teeth were exposed to either Streptococcus gordonii and Actinomyces oris or S. gordonii and Porphyromonas gingivalis for 10 weeks. Bacterial invasion was assessed in a depth of $1 \mathrm{~mm}$ to the root surface. Human pulpal cells were seeded into the cavities to assess the expression of interleukin-8 (IL-8), monocyte chemoattractant protein-1 (MCP-1), and matrix metalloproteinase-3 (MMP-3) by real-time polymerase chain reaction and immunoassay.

Results The percentage of teeth with bacteria detected in dentine was higher when teeth received scaling than when they were untreated: $66.6 \%$ versus $44.4 \%$ when exposed to A. oris/S. gordonii, and $50 \%$ versus $25 \%$ when exposed to P. gingivalis/ $S$. gordonii $(p=0.043)$. Scaling had no impact on IL-8 and MMP-3 expression in pulpal cells. $P$. gingivalis/S. gordonii caused higher levels of IL-8, MCP-1, and MMP-3 than A. oris/S. gordonii $(p=0.003, p=0.011, p=0.037)$.

Conclusion Scaling supports the penetration of bacteria into the dentine of extracted human teeth. $P$. gingivalis may affect the immune response in pulpal cells.

Clinical relevance Root surface debridement with hand instruments may facilitate bacterial penetration. Other kinds of mechanical instrumentation in this experimental setting should be investigated.
\end{abstract}

Keywords Bacterial invasion into dentine $\cdot$ Bacterial penetration into dentinal tubules $\cdot$ Endodontic-periodontal lesion $\cdot$ Mixed species biofilm $\cdot$ Periodontal therapy $\cdot$ Proinflammatory response $\cdot$ Pulpal cells $\cdot$ Scaling

Alex SJ Schatt and Miro Stoffel contributed equally and share the second position

Alexandra Stähli

alexandra.staehli@zmk.unibe.ch

1 Department of Periodontology, School of Dental Medicine, University of Bern, Freiburgstrasse 7, 3010 Bern, Switzerland

2 Center of Electron Microscopy, University Hospital Jena, Jena, Germany

3 Department of Oral Biology, School of Dentistry, Medical University of Vienna, Vienna, Austria

4 Department of Conservative Dentistry, Sigmund Freud University, Vienna, Austria

\section{Introduction}

The tooth's pulpal tissue together with the surrounding periodontal apparatus form one biologic unit, a continuum where alterations in one compartment may have an impact on the others. Therefore, also therapeutic interventions in one compartment potentially can exert broader effects. Mechanical instrumentation, the standard treatment of periodontitis, aims to eliminate hard and soft bacterial deposits on the root surface and results in improved clinical outcomes such as reduced bleeding on probing (BoP) and decreased probing pocket depth (PPD) [1, 2]. However, repeated or extensive scaling and root planning alters the surface of the root cementum and can thus have an impact on the pulpal tissue. Root cementum is a thin continuous mineralized tissue layer that forms the 
outer cover of the root and connects the periodontal ligament and the dentine [3]. It serves as a site of attachment for the Sharpey's fibers and therefore plays a crucial role for tooth attachment [4]. When bacterial contamination and the immune host response spread towards the apex on the root cementum, the question arises whether bacteria, endotoxins, or cytokines are able to invade into the cementum layer.

As a matter of fact, subgingival mechanical instrumentation during active (i.e., nonsurgical and surgical) and supportive periodontal therapy results in the removal of more or less cementum which can eventually lead to exposure of dentinal tubules, pulp injury, or hypersensitivity [5]. Root substance removal by scaling and root planing with hand instruments was measured applying different known stroke forces. Substance removal per stroke varied between 6.8 and 20.6 micron depending on the force used. Interestingly, along 40 strokes, the mean force per stroke increased while the substance removal per stroke decreased resulting in a cumulative loss of 148.7 microns for low and 343.3 micron for high forces [6].

Periodontal disease and instrumentation of the root surface might influence pulpal tissues due to their close anatomical relationship: primarily through exposed dentinal tubules, lateral or accessory canals, and via the apical foramen. Once dentine tubules become exposed, microbial inflammation is potentially able to spread bi-directionally. As such, it is not surprising that the microbiota infecting the periodontium and the root canal systems are highly similar. Disease transmission and microbial similarity has been demonstrated by many studies [7-9] and is further supported by the similar cellular infiltrate in the pulpal and periodontal tissues [10]. Analysis of microbiomes of endodontic-periodontal lesions before and after root canal treatment shows a highly diverse microbial community with bacteria surviving root canal treatment. Hereby, dentinal tubules might serve as niches for bacterial survival. Endodontic bacteria either in monomicrobial or in polymicrobial aggregates were detected in the dentinal tubules of extracted infected teeth [11]. Actinomyces sp. is abundant in deep dentine lesions [12] and is found in endodontic infections [13]. Also for yeasts, in particular Candida albicans, it is possible to colonize the dentinal tubules system as well as the periodontal pocket [14]. Despite the similarities of the microbiota of the pulp and the periodontium, periodontal pockets show a higher diversity in species than in the root canal system $[15,16]$. In endodontic samples of teeth affected by periodontitis periodontal pathogens including Aggregatibacter actinomycetemcomitans, Porphyromonas gingivalis, Treponema denticola, or Tannerella forsythia could be detected [17].

On the other side, periodontal inflammation can affect the vitality of the pulp. In periodontally compromised teeth without restorations and caries lesions, histological signs of pathology were found adjacent to accessory canals in $79 \%$ of teeth
[18]. Further, a positive association between the severity of periodontal disease and histological changes in the pulp was detected [19]. More attachment loss was correlated with more pronounced signs of pathological changes [19]. There are, however, contradictory results concerning the effect of periodontal disease on the pulp. Clinical studies implied that periodontal disease only rarely results in pulp necrosis as was suggested before. Over a time period of 4 to 13 years, only few teeth with advanced periodontal disease experienced pulpal necrosis and needed root canal treatment [20]. On cellular level, only few to no inflammatory cells of periodontally involved roots were reported by Haskell et al. when resecting vital roots [21].

To date, evidence on bacterial challenges on the root surface after mechanical instrumentation and their impact on pulpal cells is scarce. The present study used a 10 -week biofilm cultivation to determine (i) the impact of mechanical instrumentation on the penetration depth of bacteria from the root surface into dentine and (ii) the cellular response of pulpal cells seeded into the pulpal cavum of extracted scaled and native teeth that were exposed to two-species bacterial mixtures (i.e., Streptococcus gordonii with Actinomyces oris as well as $S$. gordonii with $P$. gingivalis), and (iii) differences between the two bacterial compositions.

\section{Material and methods}

\section{Preparation of extracted teeth}

A total of 102 extracted adolescent premolars or upper wisdom teeth were used. The teeth had been extracted over the last years at the School of Dental Medicine, Bern, and anonymously stored in $1 \%$ chloramine for a long time before storing in $0.9 \% \mathrm{w} / \mathrm{v} \mathrm{NaCl}$ solution. The volunteers were informed about the use of their extracted teeth in research, and their oral consent was obtained. According to the guidelines, no previous approval from the Cantonal Ethical Committee, Bern, (KEK) was necessary as the teeth were categorized as "irreversibly anonymised." Pulpal chambers and root canals were instrumented $1 \mathrm{~mm}$ short of the apical foramen using endodontic files and ProTaper Next instruments up to 40.06 (PTN; Dentsply Maillefer, Ballaigues, Switzerland). During instrumentation, the teeth were irrigated with $3 \mathrm{ml}$ of $\mathrm{NaOCl}$ solution (Dakin's solution, natrii hypochlorosi 3\%; Hänseler, Swiss Pharma, Herisau, Switzerland). To remove remnants of the disinfecting solution, the teeth were stored in $0.9 \% \mathrm{w} / \mathrm{v}$ $\mathrm{NaCl}$ solution for two months with exchange of the solution every third day. Half of the teeth then received scaling and root planing with Gracey curettes (HuFriedy, Chicago, IL, USA) for $4 \mathrm{~min}$ by a periodontist. The apices of the teeth were closed with composite (Tetric Evo Flow A2, Ivoclar Vivadent, Schaan, Liechtenstein) and Syntac system (Ivoclar Vivadent, 
Schaan, Liechtenstein) in order to prevent apical leakage. Predetermined breaking lines in the longitudinal axis were produced with a diamond bur in half of the scaled and half of the native teeth. Figure 1 depicts the experimental setting and the groups of the extracted teeth. Pulpal chambers were then filled with a sterile cotton pellet and closed with a temporary material (Telio CS, Ivoclar Vivadent, Schaan, Liechtenstein) using a curing lamp (Bluephase, Ivoclar Vivadent, Schaan, Liechtenstein). The teeth were embedded in vertical direction in an empty pipette tip box using silicone for their fixation (Putty regular set, Provil novo Dose Refill, Heraeus Kulzer GmbH, Hanau, Germany). Before the experiments, they were autoclaved in the box half filled with distilled water for $20 \mathrm{~min}$ at $121^{\circ} \mathrm{C}$.

\section{Microbial penetration of roots of the teeth}

The following microbial strains were used: S. gordonii ATCC 10558, A. oris MG1, and P. gingivalis ATCC 33277. Strains were cultivated on trypticase soy agar [22] plates (Oxoid, Basingstoke, GB) with $5 \%$ of sheep blood for $24 \mathrm{~h}$ at $37^{\circ} \mathrm{C}$ (A. oris MG1 and P. gingivalis ATCC 33277 in anaerobic conditions). Thereafter, microorganisms were suspended in $0.9 \% \mathrm{w} / \mathrm{v} \mathrm{NaCl}$ solution (OD600 $\mathrm{nm}=1$ ). Then, suspensions of $S$. gordonii were mixed 1:1 either with $A$. oris or with $P$. gingivalis, before adding to the nutrient broth ((WilkinsChalgren broth (Oxoid) with $10 \mu \mathrm{g} / \mathrm{ml} \beta$-NAD (Merck KGaA, Darmstadt, Germany)) brain heart infusion broth Oxoid). Extracted teeth had been incubated in the nutrient media with bacteria for 10 weeks. For half of the teeth, S. gordonii and A. oris were used for the other half $S$. gordonii and $P$. gingivalis. The boxes containing the teeth were opened in a laminar air flow cabinet and the roots were inoculated with one of the two bacterial suspensions. The boxes were incubated in an anaerobic chamber at $37{ }^{\circ} \mathrm{C}$ for 10 weeks. Every week, new bacteria were added and bacterial growth in nutrient media was checked. Exchange of the nutrient medium was performed every 3 days.

\section{Cell culture}

Dental pulpal cells (DPC) were harvested from the extracted donor teeth from patients who had given informed and written consent. As before, the volunteers were informed about the use of their extracted teeth in research and according to the guidelines, no previous approval from the Cantonal Ethical Committee KEK was necessary as the teeth were categorized as "irreversibly anonymised." Cells growing out from dental pulp tissue were incubated in cell culture medium (DMEM, Invitrogen; Carlsbad, CA, USA ) with $10 \%$ fetal bovine serum (FBS, Invitrogen). As fibroblasts within the dental pulp cell population show a high proliferation rate, it can be assumed that the dental pulp cell population predominantly consists of fibroblasts. A total of three strains of pulp cells were established by explant cultures and fewer than 10 passages were used for the experiments. Cells were maintained in a humidified atmosphere of $5 \% \mathrm{CO}_{2}$ and at $37{ }^{\circ} \mathrm{C}$. The cell culture medium was exchanged every other day and the FBS was reduced to $1 \%$, one day prior to the experiments. Cells were seeded at a concentration of 300,000 cells $/ \mathrm{cm}^{2}$, i.e., 5000 cells into the pulpal chambers of the extracted teeth using FBS-free cell culture medium.

\section{Scanning electron microscopy}

For scanning electron microscopy [23], the teeth were split in half by fracturing, fixed with $2.5 \%$ glutaraldehyde in cacodylate buffer for $60 \mathrm{~min}$, then washed twice with cacodylate buffer. Following dehydration with ethanol in ascending concentrations $(30 \%, 50 \%, 70 \%, 80 \%, 90 \%, 100 \%)$, specimen were critical point-dried using liquid $\mathrm{CO}_{2}$ and sputtered with a 10-nm layer of gold. Microscopical analysis

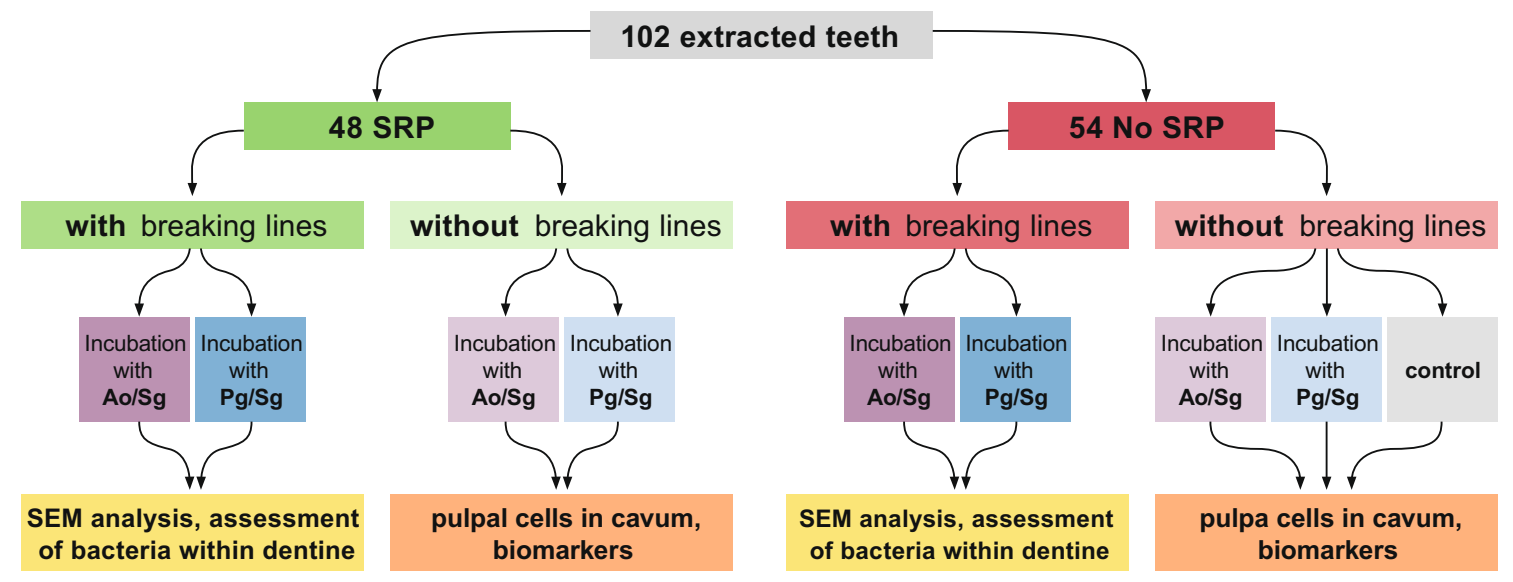

Fig. 1 Flowchart of the experimental setting and the different groups of used teeth. SRP, scaling and root planning; Ao, Actinomyces oris MG1; Pg, Porphyromonas gingivalis ATCC 33277; Sg, Streptococcus gordonii ATCC 10558 
was performed using a scanning electron microscope (ZEISS LEO-1530, Carl Zeiss, Oberkochen, Germany) at an acceleration voltage of $8 \mathrm{kV}$.

\section{Penetration of bacteria into dentin}

For assessing the penetration depth of bacteria into dentin, the teeth were longitudinally split in two halves. With a sterile rose bur, dentine specimens were collected out in a distance of about $1 \mathrm{~mm}$ to the root surface. The debris were placed into an Eppendorf tube filled with $100 \mu \mathrm{L}$ of Wilkins-Chalgren broth with NAD and distributed on TSA plates with an inoculating loop. After anaerobic incubation for 7 days, bacterial growth was recorded.

\section{RT-PCR and immunoassay}

mRNA expression of interleukin (IL)-8, monocyte chemoattractant protein 1 (MCP-1 = CCL2), and matrix metallo-protease (MMP)-3 were quantified in pulpal cells. RNA extraction was performed using the innuPREP Mini kit (Analytic Jena, Jena, Germany) and cDNA was generated from 100 ng total RNA using the GoScriptTM Reverse Transcription System (Promega, Madison WI, USA) according to the manufacturer's instructions. Thereafter, real-time PCR using GoTaq ${ }^{\circledR}$ qPCR Master Mix (Promega) with respective primers (IL-8 fwd.: 5'-CAC TGC GCC AAC ACA GAA AT-3', rev.: 5'-TGG CCC TTG GCC TCA ATT TT-3', accession \# BC013615.1; MCP-1 fwd.: 5'-GAT CTC AGT GCA GAG GCT CG-3', rev.: 5'-TTT GCT TGT CCA GGT GGT CC-3', accession \# S71513.1; MMP-3: 5'-CAC CAG ATT TGC CAA AAG ATG CT-3'; 5'-TTG AGA CAG GCG GAA CCG AG-3', accession \# NM_002422.5; GAPDH [24]) was performed according to the manufacturer's instructions. Amplification was performed with the QuantStudio 3 Real-Time PCR System (Thermo Fischer, Waltham, MA, USA). Relative gene expression was calculated with the delta delta CT method.

\section{Statistical analysis}

Statistical analysis was based on the Kruskal-Wallis test and Mann-Whitney $U$ test. For contingency tables, Fisher's exact test was used. Analyses were performed using SPSS 26.0 (IBM Corporation, New York, NY, USA). Significance was set at $p<0.05$.

\section{Results}

From the 102 teeth at the beginning, only 91 could be included in the final analysis. In part, leakages occurred and these teeth had to be removed from final analysis.

\section{Invasion of mixed cultured strains}

Both bacterial mixtures were able to penetrate into dentine. For $A$. oris/S. gordonii as well as $P$. gingivalis/S. gordonii, scaled teeth showed a trend for a higher percentage of teeth with bacteria infected dentine compared to native teeth (Fig. 2). In the scaled group, $66.6 \%$ of the teeth exposed to A. oris/ $S$. gordonii showed bacterial penetration through dentine, whereas in the native group, only $44.4 \%$ showed bacteria within dentine. For the teeth exposed to $P$. gingivalis/ S. gordonii, $50 \%$ of the scaled teeth were positive versus $25 \%$ in the native group. When taking all the scaled teeth together and comparing them with the non-scaled teeth, the difference reached statistical significance $(p=0.043)$.

\section{Scanning electron micrographs}

To visualize the results of the cultures, we also examined SEM images. At the scaled teeth, high amounts of bacteria were found in the surface irregularities while the native teeth showed only few bacteria attached to their surface. This was observed for both bacterial mixtures A. oris/S. gordonii (Fig. 3) and $P$. gingivalis/S. gordonii (Fig. 4). A few bacteria are visible deeper within the dentinal tubules.

\section{mRNA expression of inflammatory mediators}

To determine the effect of scaling and root planing on proinflammatory cytokine expression, pulpal cells were seeded into the extracted and biofilm exposed roots. Compared to noncontaminated controls and non-treated contaminated teeth, the scaled teeth did not show increased expression of any mediator. However, when comparing the bacterial mixtures (independent whether the teeth were scaled or not), there was a higher level of IL-8, MCP-1, and MMP-3 mRNA expression when the teeth were exposed to $P$. gingivalis mixed with

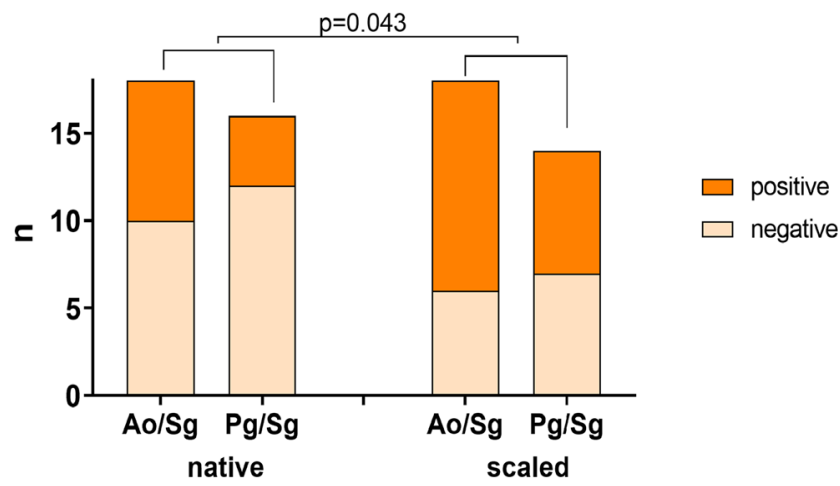

Fig. 2 Dentine samples tested positively for invasion of mixed cultured strains (Actinomycis oris MG1/Streptococcus gordonii ATCC 10558 (Ao/Sg), Porphyromonas gingivalis ATCC 33277/S. gordonii ATCC $10558(\mathrm{Pg} / \mathrm{Sg}))$ in a depth of about $1 \mathrm{~mm}$ to the surface 

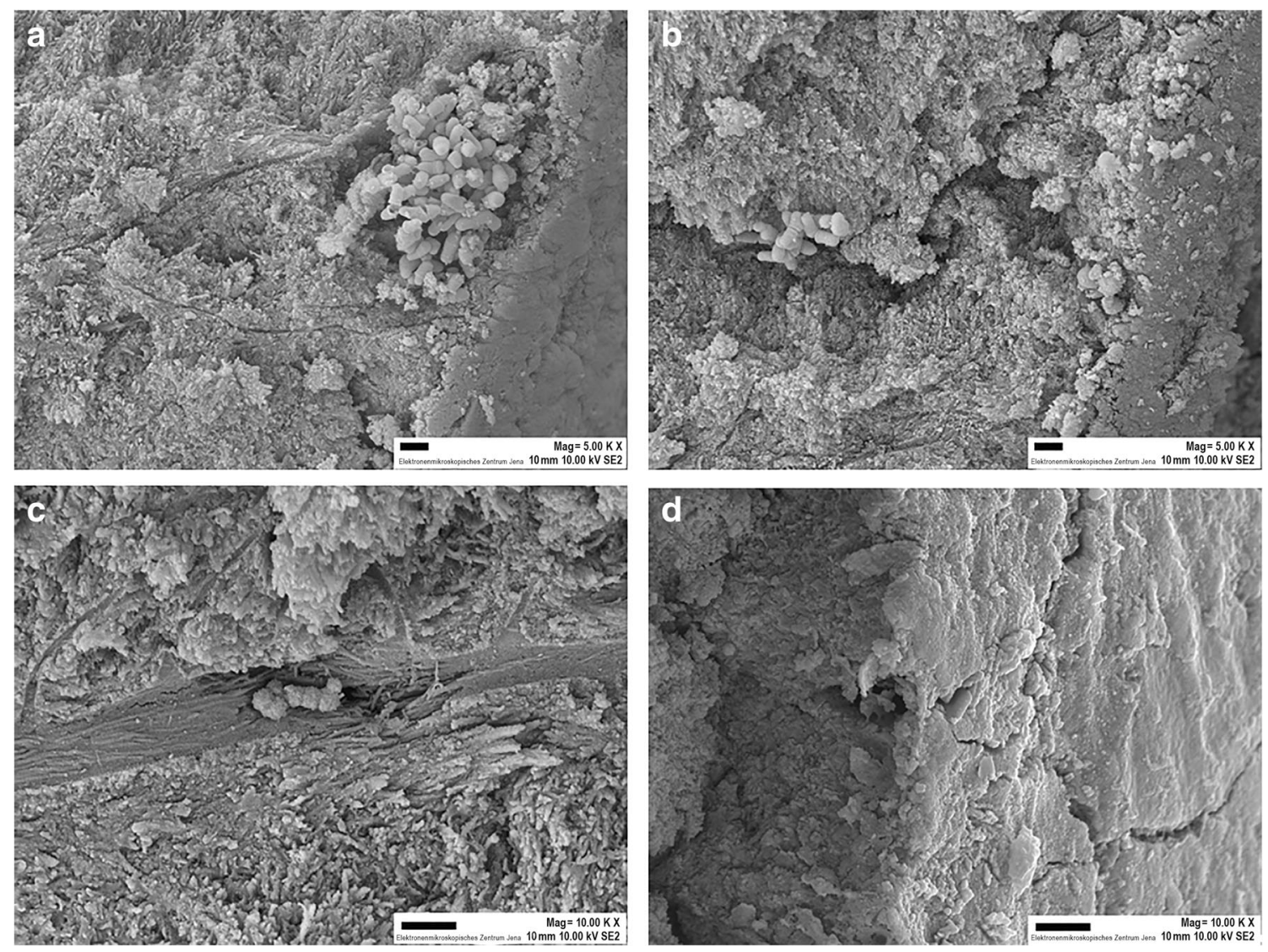

Fig. 3 SEM images of fracture surfaces of root dentine revealing the infiltration of bacteria after contamination with Actinomycis oris MG1/ Streptococcus gordonii ATCC 10558. a, b, c Scaled teeth: bacteria are located in high numbers in the irregularities close to the outer surface (a),

S. gordonii in comparison with the mixture A. oris/S. gordonii $(p=0.003, p=0.011, p=0.037)$ (Fig. 5).

\section{Discussion}

In this in vitro study, we assessed the impact of mechanical instrumentation first on the penetration of bacteria into dentinal tubules and second on cellular responses of pulpal cells. The intent was to simulate the clinical exposure of root dentin either scaled or native to bacterial biofilm. For this purpose, the extracted adolescent premolar and upper third molar teeth were incubated in a two-species bacterial biofilm for 10 weeks. The major findings are that the instrumentation of the teeth affected the penetration of bacteria into dentine and furthermore that the expression of tested inflammatory mediators of pulpal cells was influenced by the bacterial species however not by instrumentation.

Particular emphasis in this study was set on the transmission of bacteria through dentine and the assumption that dentinal tubules opened by scaling and root planing are more patent for bacteria and their toxins. In periodontally diseased teeth, it has been shown that most bacteria

they are able to penetrate into depth (b and c). d Native teeth. Only a few bacteria are attached to the outer surface. Magnification (a, b) $5.000 \times,(\mathbf{c}$, d) $10.000 \times$. Scale bar $=1 \mu \mathrm{m}$

are located in the outer $300 \mu \mathrm{m}$ of dentinal tubules [25]. Here, the teeth were continuously incubated for a time period of 10 weeks to allow bacteria to spread into dentinal tubules. Based on our experimental approach, we discovered more bacterial penetration after mechanical instrumentation. Bacteria were observed within the root dentine for both two-species biofilms. Of note, the adolescent teeth generally show larger tubules while older teeth are more likely to exhibit signs of obliteration and sclerosis. This might have facilitated bacterial transmission. Co-culture of two bacterial species was chosen because co-culture of bacteria is closer to the in vivo situation as it is for example in periodontal disease. Furthermore, it has been shown that penetration of bacteria into dentinal tubules depends on bacterial species and on the complexity of the biofilm, whereby single species showed a different penetration pattern than co-culturing of bacteria [26]. In that study, the penetration of bacteria into dentine originated from the root canal. Penetration into the inner and middle third of the root dentin was detected for $S$. gordonii, $P$. gingivalis, and $A$. oris. Interestingly, when $P$. gingivalis and $A$. oris were co-cultured with $S$. gordonii, penetration until the outer third has been observed for the combination with 

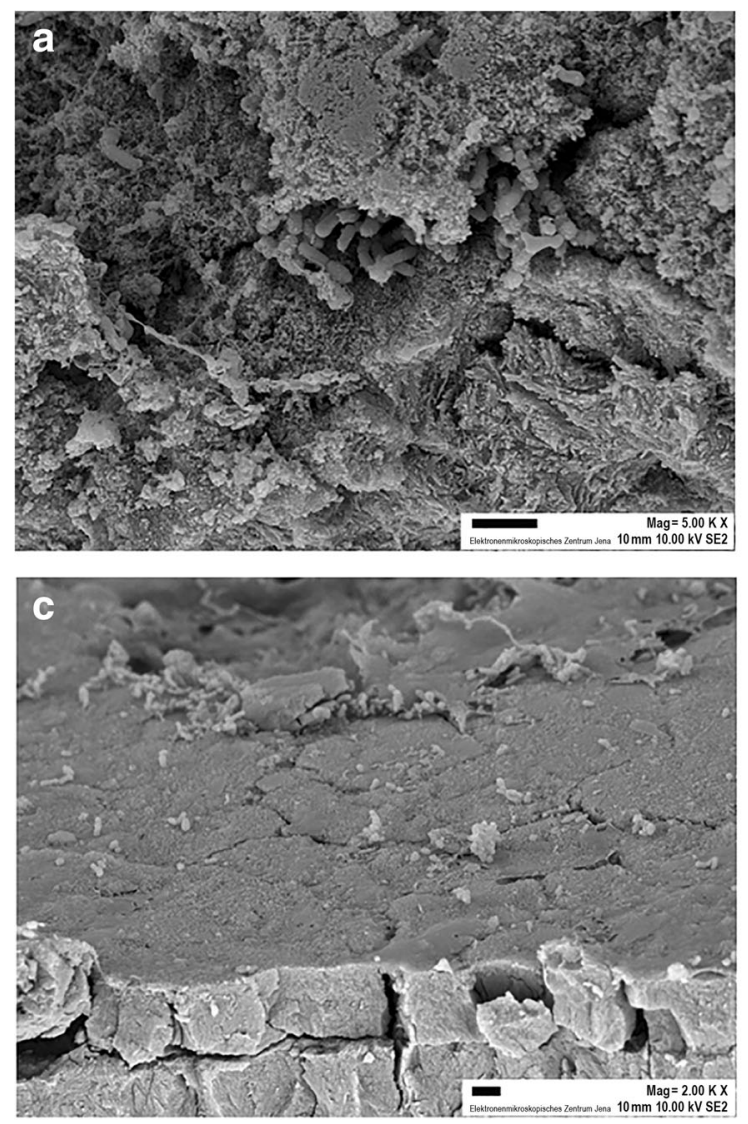

Fig. 4. SEM images of fracture surfaces of root dentine revealing the infiltration of bacteria after contamination with Porphyromonas gingivalis ATCC 33277/Streptococcus gordonii ATCC 10558. a, b Scaled teeth: bacteria are located in high numbers in the irregularities at

A. oris but not $P$. gingivalis. [26]. In the present study, there might be by trend more penetration for A. oris/ $S$. gordonii than for $P$. gingivalis/S. gordonii, but the results failed statistical significance. Others showed that the recognition of streptococcal cell wall-anchored polypeptides of the antigen I/II family accounts for the ability of $P$. gingivalis to invade dentinal tubules when in co-culture with S. gordonii but not with Streptococcus mutans [27]. This interplay of bacterial co-aggregation might play a role in the etiopathology of endodontic-periodontal lesions.

SEM images confirmed the penetration of bacteria into the dentinal tubules from the root surfaces. Further, there was a large number of bacteria visible in irregularities at the root surface after scaling. Scaling increases in vitro surface roughness of root surfaces which is accompanied by higher adhesion of Streptococcus sanguinis [28]. Smoother surfaces and less bacterial attachment in comparison with scaling are observed after ultrasonication [28].

Although histology has shown differences in pulpal tissue of teeth with moderate-to-severe chronic periodontitis [19], we found no differences in the gene and protein expression of proinflammatory cytokines of pulpal cells between the two groups (native vs scaled). However, when comparing the
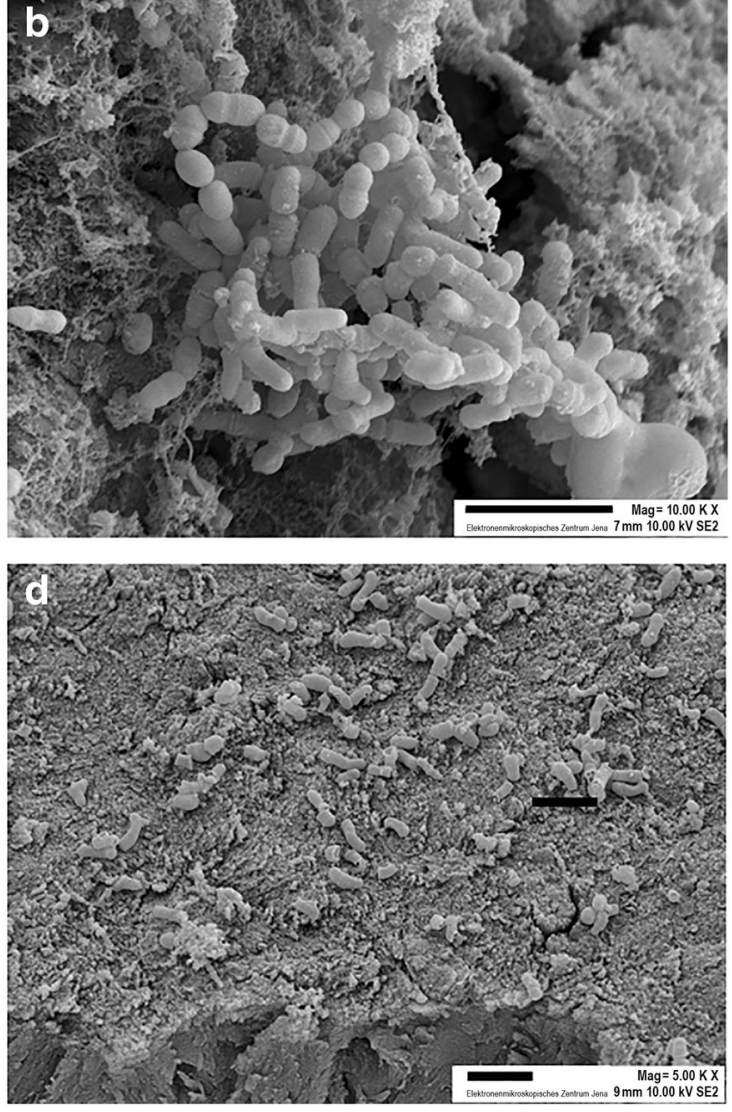

the outer surface. $\mathbf{c}, \mathbf{d}$ Native teeth display an intact layer of cementum with only a few attached bacteria. Magnification (a, d) $5.000 \times$, (b) $10.000 \times$, (c) $2.000 \times$. Scale bar $=2 \mu \mathrm{m}$

different bacterial mixtures, irrespective of the two groups of teeth, $P$. gingivalis/S. gordonii induced a significantly higher mRNA expression of all inflammatory mediators than A. oris/ $S$. gordonii did. This effect might be related to gingipains. It can be assumed that gingipains can penetrate into the pulpal chamber. Already Bergenholtz and Lindhe suggested a pathway of communication between dentinal tubules, the periodontium, and the pulp [29]. In an animal model, it was shown that application of bacterial plaque to dentin readily caused pulpal inflammation, while occlusion of exposed dentin had a protective effect to the pulp [30,31].

Gingipains have been shown to regulate the expression of MMPs and of tissue inhibitors of metalloproteinases (TIMPs) in oral fibroblasts and epithelial cells thus contributing to tissue destruction [32]. The Arg-gingipains enhance mRNA of IL-8 in gingival fibroblasts [33]. Further, challenging of human gingival fibroblasts with live $P$. gingivalis resulted in an increase of IL-8 and MCP-1 mRNA expression [34]. Both IL-8 and MCP-1 are important chemoattractant cytokines [35]. For MMP-3, an antiinflammatory function in pulp infection is suggested [35], expression might be mediated also via IL-1[36].

Some limitations need to be considered. First, leakage at the apexes or accessory canals might have concealed possible 
Fig. 5 Interleukin (IL)-8 (a), monocyte chemoattractant protein $1(\mathrm{MCP}-1)(\mathbf{b})$, and matrix metallo-protease (MMP)-3 (c) mRNA expression in pulpal cells seeded into pulpal cavities after the teeth had been exposed to mixed biofilms for 10 weeks. Medians and interquartile ranges are presented
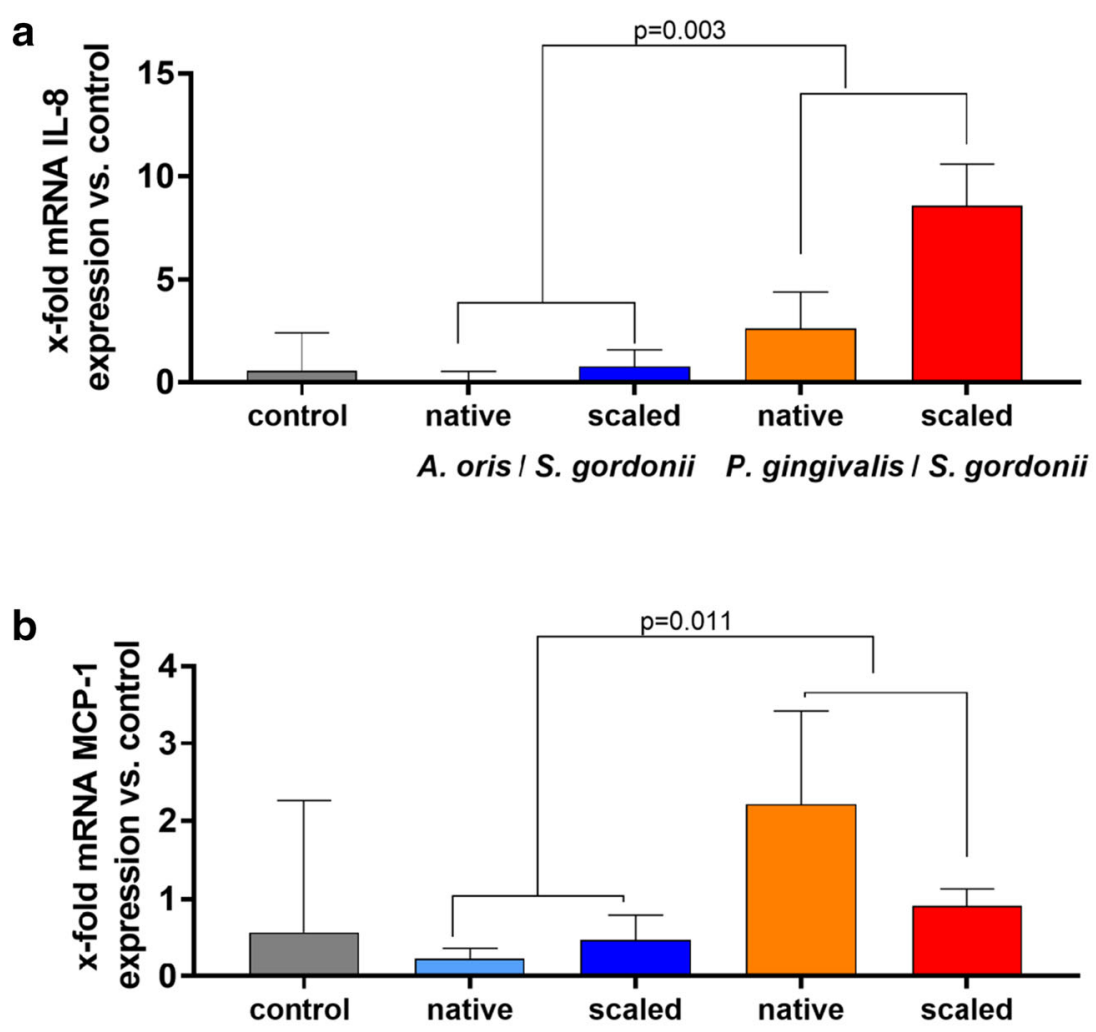

A. oris / S. gordonii P. gingivalis / S. gordonii

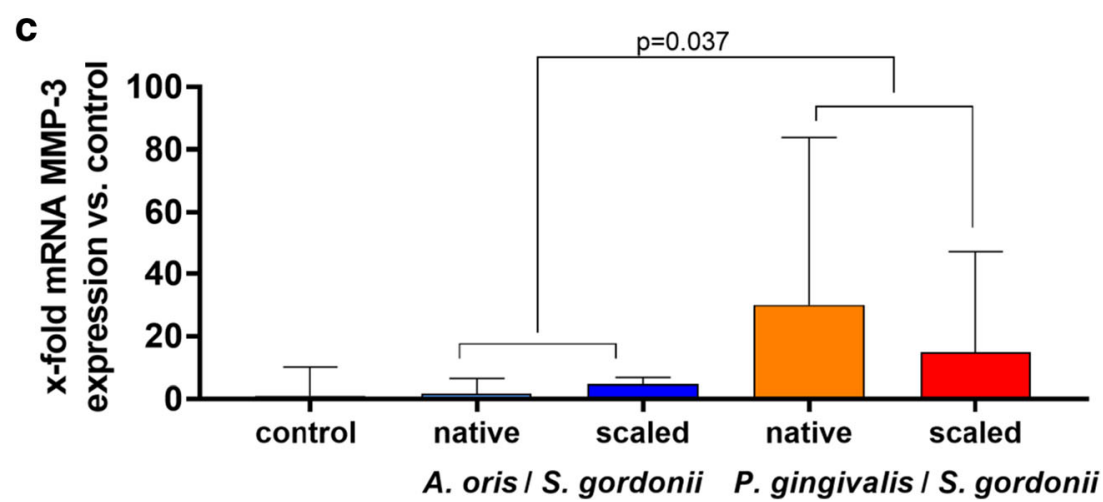

differences among groups. Second, a healthy pulp is a complex tissue consisting of a panoply of cells. Third, the nonvital extracted teeth present different physical characteristics such as for example the redox potential and this might have severe consequences of bacterial transmission through dentinal tubules. Fourth, pulpal cells were not seeded into the pulpal chambers until the end of 10 weeks of biofilm incubation. And finally, it must be considered that in the clinical situation of a vital tooth, various defense mechanisms against a possible penetration of bacterial toxins or bacteria are present. This involves a physiological pulpal tissue pressure resulting in an outward flow through the dentinal tubules. When bacterial toxins reach the dental pulp, an inflammatory process occurs; this will initiate the deposition of tertiary dentine in the tubules and increase the above mentioned tissue pressure. Thus, the clinical implication of these findings might be taken with caution and requires future research.

Our study provides novel insights into the effects of root instrumentation on pulpal cell response when exposed to bacterial biofilm. Our experiments further indicated that penetration of bacteria through the dentine was more observed in the scaled group than in the group with the native teeth. Since the teeth were endodontically instrumented, we assume that in root canal-treated teeth, similar penetration patterns might be observed. SEM images showed a more pronounced colonization of bacteria at the surfaces of the scaled teeth, in particular in 
irregularities. Therefore, it has to be pointed out that a smooth root surface might be crucial in preventing massive bacterial adherence. In this respect, other kinds of mechanical instrumentation in this experimental setting should be investigated.

Previously, cementum of periodontally diseased root surfaces was believed to harbor bacteria and bacterial endotoxins, and therefore the removal of the "diseased cementum" was considered mandatory to allow periodontal healing [29, 37]. Later, it was shown that excessive removal of cementum is not necessary to achieve periodontal health [38]. Findings from an experimental study in dogs revealed that healing was similar whether or not the previously exposed root cementum had been removed [39]. Indeed, in vitro penetration of Escherichia coli lipopolysaccharide (LPS) into root cementum was detected neither in the periodontally healthy nor in the diseased teeth [40]. The binding of the LPS was limited to the root surface and furthermore seemed rather weak. It was further shown that $99 \%$ of LPS could be removed by relatively gentle procedures including washing or gentle brushing for $1 \mathrm{~min}$ with a slow rotating brush [41]. Consequently, the preservation of cementum was supported in order to enhance cell attachment and regeneration. But our data suggest that cellular response to bacterial challenge to the pulp depends not on the instrumentation but on the presence of periodontal pathogens. Following this, removal of the bacteria being associated with periodontal disease is crucial.

From a clinical point of view, the available data indicate that mechanical instrumentation of diseased root surfaces can be performed less aggressively with respect to cementum removal. We recently showed that compared to hand instrumentation, the application of ultrasonication and air-polishing with erythritol prevents from substance loss while providing a smooth surface with nearly no residual biofilm [42]. It might be of interest to investigate further these approaches regarding the endodontic-periodontal lesion.

\section{Conclusion}

Root surface debridement with hand instruments may remove root cementum, which in turn facilitates bacterial penetration from the periodontal pocket and the oral cavity into the dentinal tubules system especially in the root canal-treated teeth where a cellular defense to bacterial penetration is lacking. In vital teeth, periodontal pathogens may influence pulpal response.

Acknowledgments We thank Prashanthnj Sivapatham for technical assistance and Granziano Zappala for instrumentation of root canals.

Funding Open access funding provided by University of Bern. This study was supported by the Department of Periodontology, University of Bern.

\section{Compliance with ethical standards}

Conflict of interest The authors declare that they have no conflict of interest.
Ethical approval This study used extracted human teeth irreversibly anonymized. No ethical approval was necessary.

Informed consent Oral consent was obtained from the volunteers to use their extracted teeth in research.

Open Access This article is licensed under a Creative Commons Attribution 4.0 International License, which permits use, sharing, adaptation, distribution and reproduction in any medium or format, as long as you give appropriate credit to the original author(s) and the source, provide a link to the Creative Commons licence, and indicate if changes were made. The images or other third party material in this article are included in the article's Creative Commons licence, unless indicated otherwise in a credit line to the material. If material is not included in the article's Creative Commons licence and your intended use is not permitted by statutory regulation or exceeds the permitted use, you will need to obtain permission directly from the copyright holder. To view a copy of this licence, visit http://creativecommons.org/licenses/by/4.0/.

\section{References}

1. Badersten A, Nilveus R, Egelberg J (1984) Effect of nonsurgical periodontal therapy. II. Severely advanced periodontitis. J Clin Periodontol 11(1):63-76. https://doi.org/10.1111/j.1600-051x. 1984.tb01309.x

2. Badersten A, Nilveus R, Egelberg J (1984) Effect of nonsurgical periodontal therapy. III. Single versus repeated instrumentation. J Clin Periodontol 11(2):114-124. https://doi.org/10.1111/j.1600051x.1984.tb00839.x

3. Bosshardt DD, Selvig KA (1997) Dental cementum: the dynamic tissue covering of the root. Periodontol 13:41-75. https://doi.org/ 10.1111/j.1600-0757.1997.tb00095.x

4. Stern IB (1964) An electron microscopic study of the cementum, Sharpey's fibers and periodontal ligament in the rat incisor. Am J Anat 115:377-409. https://doi.org/10.1002/aja.1001150302

5. von Troil B, Needleman I, Sanz M (2002) A systematic review of the prevalence of root sensitivity following periodontal therapy. J Clin Periodontol 29(Suppl 3):173-177; discussion 195-176. https:// doi.org/10.1034/j.1600-051x.29.s3.10.x

6. Zappa U, Smith B, Simona C, Graf H, Case D, Kim W (1991) Root substance removal by scaling and root planing. J Periodontol 62(12):750-754. https://doi.org/10.1902/jop.1991.62.12.750

7. Tanner AC, Visconti RA, Holdeman LV, Sundqvist G, Socransky SS (1982) Similarity of Wolinella recta strains isolated from periodontal pockets and root canals. J Endod 8(7):294-300. https://doi. org/10.1016/S0099-2399(82)80278-1

8. Kipioti A, Nakou M, Legakis N, Mitsis F (1984) Microbiological findings of infected root canals and adjacent periodontal pockets in teeth with advanced periodontitis. Oral Surg Oral Med Oral Pathol 58(2):213-220. https://doi.org/10.1016/0030-4220(84)90139-7

9. Kobayashi T, Hayashi A, Yoshikawa R, Okuda K, Hara K (1990) The microbial flora from root canals and periodontal pockets of non-vital teeth associated with advanced periodontitis. Int Endod J 23(2):100-106. https://doi.org/10.1111/j.1365-2591.1990. tb00847.x

10. Bergenholtz G, Lindhe J (1978) Effect of experimentally induced marginal periodontitis and periodontal scaling on the dental pulp. $\mathrm{J}$ Clin Periodontol 5(1):59-73. https://doi.org/10.1111/j.1600-051x. 1978.tb01907.x

11. Taschieri S, Del Fabbro M, Samaranayake L, Chang JW, Corbella S (2014) Microbial invasion of dentinal tubules: a literature review and a new perspective. J Investig Clin Dent 5(3):163-170. https:// doi.org/10.1111/jicd.12109 
12. Liu G, Wu C, Abrams WR, Li Y (2020) Structural and functional characteristics of the microbiome in deep-dentin caries. J Dent Res 99(6):713-720. https://doi.org/10.1177/0022034520913248

13. Li X, Zhu XF, Zhang CF, Cathro P, Seneviratne CJ, Shen S (2013) Endodontic bacteria from primary and persistent endodontic lesions in Chinese patients as identified by cloning and $16 \mathrm{~S}$ ribosomal DNA gene sequencing. Chin Med J 126(4):634-639

14. Rotstein I (2017) Interaction between endodontics and periodontics. Periodontol 74(1):11-39. https://doi.org/10.1111/prd.12188

15. Gomes BP, Berber VB, Kokaras AS, Chen T, Paster BJ (2015) Microbiomes of endodontic-periodontal lesions before and after chemomechanical preparation. J Endod 41(12):1975-1984. https://doi.org/10.1016/j.joen.2015.08.022

16. Kurihara H, Kobayashi Y, Francisco IA, Isoshima O, Nagai A, Murayama Y (1995) A microbiological and immunological study of endodontic-periodontic lesions. J Endod 21(12):617-621. https://doi.org/10.1016/S0099-2399(06)81115-5

17. Rupf S, Kannengiesser S, Merte K, Pfister W, Sigusch B, Eschrich K (2000) Comparison of profiles of key periodontal pathogens in periodontium and endodontium. Endod Dent Traumatol 16(6):269-275

18. Seltzer S, Bender IB, Ziontz M (1963) The interrelationship of pulp and periodontal disease. Oral Surg Oral Med Oral Pathol 16:14741490. https://doi.org/10.1016/0030-4220(63)90385-2

19. Wan L, Lu HB, Xuan DY, Yan YX, Zhang JC (2015) Histological changes within dental pulps in teeth with moderate-to-severe chronic periodontitis. Int Endod J 48(1):95-102. https://doi.org/10.1111/ iej.12282

20. Bergenholtz G, Nyman S (1984) Endodontic complications following periodontal and prosthetic treatment of patients with advanced periodontal disease. J Periodontol 55(2):63-68. https://doi.org/10. 1902/jop.1984.55.2.63

21. Haskell EW, Stanley H, Goldman S (1980) A new approach to vital root resection. J Periodontol 51(4):217-224. https://doi.org/10. 1902/jop.1980.51.4.217

22. Tsai C, Hayes C, Taylor GW (2002) Glycemic control of type 2 diabetes and severe periodontal disease in the US adult population. Community Dent Oral Epidemiol 30(3):182-192. https://doi.org/ 10.1034/j.1600-0528.2002.300304.x

23. Kyaw BM, Posadzki P, Dunleavy G, Semwal M, Divakar U, Hervatis V, Tudor Car L (2019) Offline digital education for medical students: systematic review and meta-analysis by the Digital Health Education Collaboration. J Med Internet Res 21(3):e13165. https://doi.org/10.2196/13165

24. Shen Y, Li Y, Ye F, Wang F, Lu W, Xie X (2010) Identification of suitable reference genes for measurement of gene expression in human cervical tissues. Anal Biochem 405(2):224-229. https:// doi.org/10.1016/j.ab.2010.06.029

25. Adriaens PA, Edwards CA, De Boever JA, Loesche WJ (1988) Ultrastructural observations on bacterial invasion in cementum and radicular dentin of periodontally diseased human teeth. J Periodontol 59(8):493-503. https://doi.org/10.1902/jop.1988.59. 8.493

26. Stauffacher S, Lussi A, Nietzsche S, Neuhaus KW, Eick S (2017) Bacterial invasion into radicular dentine-an in vitro study. Clin Oral Investig 21(5):1743-1752. https://doi.org/10.1007/s00784-0161960-7

27. Love RM, McMillan MD, Park Y, Jenkinson HF (2000) Coinvasion of dentinal tubules by Porphyromonas gingivalis and Streptococcus gordonii depends upon binding specificity of streptococcal antigen I/II adhesin. Infect Immun 68(3):1359-1365. https://doi.org/10.1128/iai.68.3.1359-1365.2000

28. Ota-Tsuzuki C, Martins FL, Giorgetti AP, de Freitas PM, Duarte PM (2009) In vitro adhesion of Streptococcus sanguinis to dentine root surface after treatment with Er:YAG laser, ultrasonic system, or manual curette. Photomed Laser Surg 27(5):735-741. https://doi. org/10.1089/pho.2008.2324

29. Chace R (1974) Subgingival curettage in periodontal therapy. J Periodontol 45(2):107-109. https://doi.org/10.1902/jop.1974.45. 2.107

30. Bergenholtz G, Lindhe J (1975) Effect of soluble plaque factors on inflammatory reactions in the dental pulp. Scand J Dent Res 83(3): 153-158. https://doi.org/10.1111/j.1600-0722.1975.tb01193.x

31. Bergenholtz G, Reit C (1980) Reactions of the dental pulp to microbial provocation of calcium hydroxide treated dentin. Scand J Dent Res 88(3):187-192. https://doi.org/10.1111/j.1600-0722. 1980.tb01213.x

32. Andrian E, Mostefaoui Y, Rouabhia M, Grenier D (2007) Regulation of matrix metalloproteinases and tissue inhibitors of matrix metalloproteinases by Porphyromonas gingivalis in an engineered human oral mucosa model. J Cell Physiol 211(1):56 62. https://doi.org/10.1002/jcp.20894

33. Oido-Mori M, Rezzonico R, Wang PL, Kowashi Y, Dayer JM, Baehni PC, Chizzolini C (2001) Porphyromonas gingivalis gingipain- $\mathrm{R}$ enhances interleukin- 8 but decreases gamma interferon-inducible protein 10 production by human gingival fibroblasts in response to T-cell contact. Infect Immun 69(7):44934501. https://doi.org/10.1128/IAI.69.7.4493-4501.2001

34. Scheres N, Crielaard W (2013) Gingival fibroblast responsiveness is differentially affected by Porphyromonas gingivalis: implications for the pathogenesis of periodontitis. Mol Oral Microbiol 28(3): 204-218. https://doi.org/10.1111/omi.12016

35. Yoshimura T (2015) Discovery of IL-8/CXCL8 (the story from Frederick). Front Immunol 6:278. https://doi.org/10.3389/fimmu. 2015.00278

36. Ozeki N, Yamaguchi H, Hiyama T, Kawai R, Nakata K, Mogi M, Nakamura H (2015) IL-1beta-induced matrix metalloproteinase-3 regulates cell proliferation in rat dental pulp cells. Oral Dis 21(1): 97-105. https://doi.org/10.1111/odi.12219

37. Robinson PJ (1975) Possible roles of diseased cementum in periodontitis. J Prev Dent 2(3):3-5

38. Albair WB, Cobb CM, Killoy WJ (1982) Connective tissue attachment to periodontally diseased roots after citric acid demineralization. J Periodontol 53(8):515-526. https://doi.org/10.1902/jop. 1982.53.8.515

39. Nyman S, Westfelt E, Sarhed G, Karring T (1988) Role of "diseased" root cementum in healing following treatment of periodontal disease. A clinical study. J Clin Periodontol 15(7):464 468. https:// doi.org/10.1111/j.1600-051x.1988.tb01601.x

40. Nakib NM, Bissada NF, Simmelink JW, Goldstine SN (1982) Endotoxin penetration into root cementum of periodontally healthy and diseased human teeth. J Periodontol 53(6):368-378. https://doi. org/10.1902/jop.1982.53.6.368

41. Moore J, Wilson M, Kieser JB (1986) The distribution of bacterial lipopolysaccharide (endotoxin) in relation to periodontally involved root surfaces. J Clin Periodontol 13(8):748-751. https://doi.org/10. 1111/j.1600-051x.1986.tb00877.x

42. Hagi TT, Klemensberger S, Bereiter R, Nietzsche S, Cosgarea R, Flury S, Lussi A, Sculean A, Eick S (2015) A biofilm pocket model to evaluate different non-surgical periodontal treatment modalities in terms of biofilm removal and reformation, surface alterations and attachment of periodontal ligament fibroblasts. PLoS One 10(6): e0131056. https://doi.org/10.1371/journal.pone.0131056

Publisher's note Springer Nature remains neutral with regard to jurisdictional claims in published maps and institutional affiliations. 